\title{
Influence of Rotor Design on Electromagnetic Performance in Interior Permanent Magnet Machines
}

\author{
Tommaso Transi \\ Power Electronics, Machines and \\ Control Research Group \\ University of Nottingham \\ Nottingham, United Kingdom \\ tommaso.transi@nottingham.ac.uk \\ Eraldo Preci \\ Power Electronics, Machines and \\ Control Research Group \\ University of Nottingham \\ Nottingham, United Kingdom
}

\author{
Mukhammed Murataliyey \\ Power Electronics, Machines and \\ Control Research Group \\ University of Nottingham \\ Nottingham, United Kingdom \\ David Gerada \\ Power Electronics, Machines and \\ Control Research Group \\ University of Nottingham \\ Nottingham, United Kingdom
}

\author{
Michele Degano \\ Power Electronics, Machines and \\ Control Research Group \\ University of Nottingham \\ Nottingham, United Kingdom
}

\author{
Chris Gerada \\ Power Electronics, Machines and \\ Control Research Group \\ University of Nottingham \\ Nottingham, United Kingdom
}

\begin{abstract}
Nowadays, Interior Permanent Magnet Synchronous Machines (IPMSM) are widely adopted in various sectors such as automotive, railway or public transportation (ebuses, trams, etc.). Among the benefits that these machines present, they offer a number of design degrees of freedom. Furthermore, they can operate over a wide speed range, with a good flux weakening capability. One of the main challenges is to define a complete geometrical parametrization, in order to identify an optimal structure that satisfies the design requirements. In this paper, a detailed analysis of the rotor structure is carried out looking at understanding the effects of the geometrical parameters on key performance indexes (e.g. flux density harmonic content, torque capability, torque ripple, etc.). Based on the preliminary analysis, an optimization procedure is implemented for the design of a Nabla-shaped rotor to satisfy the electromechanical performance of a case study traction motor. The results are showing how an optimal machine can be designed with a reduced amount of permanent magnet, by optimizing the rotor structure.
\end{abstract}

Keywords-Interior Permanent Magnet Synchronous Machine, Nabla-shaped, Rotor Optimization, Airgap Flux Density, Harmonic Analysis.

\section{E-MOBILITY: WHERE ARE WE?}

In Europe, around $25 \%$ of the total $\mathrm{CO} 2$ emissions is caused by transport sector, which is the most polluting sector, after the energy industries field (c.a. 26\%). In particular, the road transportation is responsible for about $72 \%$ of Greenhouse Gas (GHG) emissions, followed by civil aviation $(14 \%)$ and navigation $(13 \%)$ [1].

As evidenced by the European Environment Agency (EEA) in a study presented on 2017, almost all car makers have met the $\mathrm{CO} 2$ emission targets for that year $(130 \mathrm{~g}$ $\mathrm{CO} 2 / \mathrm{km}$ ) [2], nonetheless this is still far from the 2021 emissions target $(95 \mathrm{~g} \mathrm{CO} 2 / \mathrm{km})$ set by the European Commission.

Taking into account these values, and with the aim of improving the technology in this sector, it is of paramount importance to invest in the research and optimization of the technologies: electric vehicles (EVs), hybrid or plug-in hybrid electric vehicles (HEVs, PHEVs) are just some of the available alternatives to conventional internal combustion engine vehicles (ICEs). Only by adopting "cleaner" hybrid and electric vehicles such as battery powered electric buses, trolley buses and trams can lead to a significant reduction in GHG emissions.

Each transport sector needs specific characteristic. Automotive companies always look for a faster and cheaper manufacturing processes (high volume low value production). Public transport sector (buses, trams, metros, etc.) targets a very long-life expectancy and a fault-tolerant architecture, with minimum maintenance [3]. Aviation industry, being a safety critical application, requires high reliability, and very high power and energy density, thus reduced weight (high value low volume manufacturing) [4]. In Fig. 1, a radar graph clearly shows the different importance of the aforementioned performance indexes, for different transportation sector.

In terms of electrical machines and drives, different solutions have been proposed in the past decades for the transport sector. Nowadays the family of synchronous machines is the most promising, with plenty of different topologies and technical arrangements that can provide better performances in terms of efficiency and power density, compared to the asynchronous machines [5]. Permanent magnets (PMs) made by rare earth materials (e.g. Neodymium, Samarium, etc.) can be inserted in the rotor of these machines in order to enhance torque/power production.

In this case, the different PMs arrangements can be mainly divided in three subfamilies: Surface Permanent Magnet

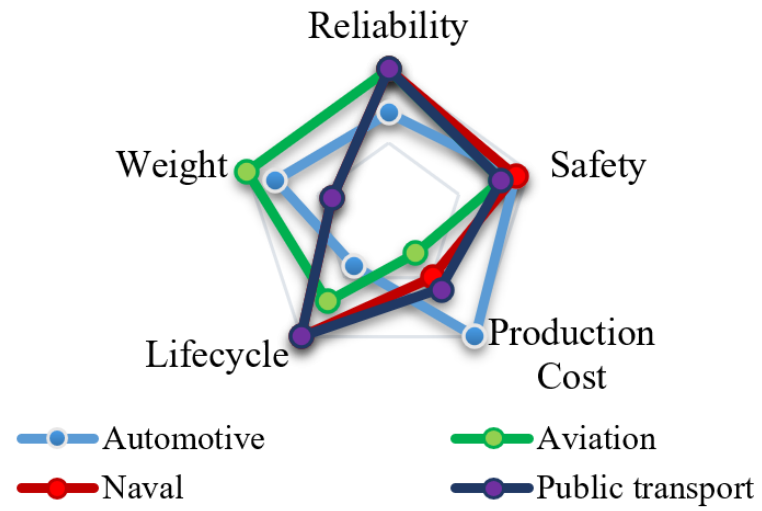

Figure 1: Radar graph showing the importance of each characteristic for the 4 types of transport cited

(SPM), Interior Permanent Magnet (IPM) and Permanent 
Magnet assisted Synchronous Reluctance (PMaSynRel) machines.

The main difference between IPM and PMaSynRel is given by the ratio of the reluctance torque, over the PM torque component: PMaSynRel machines present a higher PM torque component, compared to an IPM solution.

The torque equation in case of three-phase reluctance machines is given in (1), where $p$ represents the number of pole pairs, $\lambda_{p m}$ indicates the PM flux, $L_{d}$ and $L_{q}$ are the direct and quadrature inductances, respectively; and $i_{d}, i_{q}$ are the direct and quadrature currents flowing in the stator windings.

$$
T_{e m}=\frac{3}{2} p\left(i_{q} \lambda_{p m}+i_{q} i_{d}\left(L_{d}-L_{q}\right)\right)
$$

In (1), the main electromagnetic variables are the direct and quadrature axis inductances. In a reluctance motor within a $d$ $q$-reference frame, the $d$-axis is the path of least reluctance and the $q$-axis is the path of greater reluctance; reflecting into unequal inductances, dependent on the rotor position. Hence, when $L_{d} \neq L_{q}$ an "alignment" torque, alternatively known as the reluctance torque, is present.

IPM machines in particular, present a wide range of different arrangements, not only in terms of PM placement position, but also for the shape of the flux barriers [6]. During last years, more exotic arrangements both for PMs and barriers have been proposed such as flared-shape arrangement for magnets presented in [7] or a w-shaped magnet position in [8].

There are examples of asymmetric rotor designs, proposed to reduce vibrations [9] or asymmetric assisted barriers displacement adopted to improve torque characteristics trying to obtain the maximum value for both PM and reluctance torque components at the same current phase angle [10]. Another field that has been investigated is the flexible orientation that can be adopted using new sintered PMs in order to reduce the irreversible demagnetization risk [11].

This work is focused on one particular rotor arrangement, the so-called $\nabla$ (Nabla)-shaped geometry that has been already presented together with other similar multi-layered arrangements in [12-13], where a fair analysis of mechanical and electromagnetic performances have been proposed.

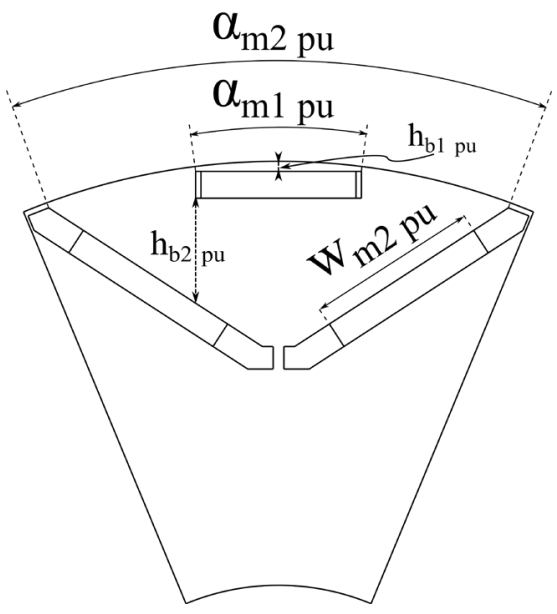

Figure 2: $\nabla$-shaped IPMSM sketch, with parameters

After having selected the desired rotor geometry, an optimisation needs to be performed in order to tailor the rotor design to the specific requirements [14]: in [15] an optimal design for a $\nabla$-shaped rotor geometry has been presented, explaining also the optimisation methodology that has been used. Another interesting study that covers not only optimisation strategy for $\mathrm{V}$-shaped geometry, but presents also a sensitivity analysis consideration for this particular case can be found in [16]. Finally, the correlation between the driving range for a given EV driven by a V-shaped IPM machine and some machine geometrical parameters is presented in [17].

\section{II. $\quad \nabla$-SHAPED GEOMETRY SENSITIVITY ANALYSIS}

\section{A. Geometry parametrization}

$\nabla$-shaped IPMSM are the subject of this work. In order to explore the pros and cons of the permanent magnet distribution in the rotor structure, a parametrization with a specific range of variables has been defined, using per unit values (pu) where applicable. This method allows a faster sensitivity analysis, simply changing a set of parameters to modify the complete geometry. Some safety factors have been inserted in the script, to ensure that minimal distances are respected, especially in critical points such as bridges and ribs, required to guarantee mechanical robustness of the rotating parts. The main parametrization factors can be found in Fig. 2: $\alpha_{m 1} p u$ and $\alpha_{m 2 ~ p u}$ indicate the displacement angles (expressed in per unit) of the first and second barriers, respectively, in relation to the available space expressed in degrees. $w_{m 2} p u$ instead, indicates the width of the PMs included in the second level barriers in per unit values, in relation to the total available space in the barriers. In conclusion, $h_{b 1} p u$ and $h_{b 2} p u$, are two distances, as defined in Fig. 2. Some of the geometrical and manufacturing specifications are reported in Table I.

Table I: Machine Specifications

E-machine geometrical specifications

$\begin{array}{cc}\text { Iron Material } & \text { M400 } \\ \text { PMs material } & \text { NdFeB } \\ \text { Shaft diameter } & 90 \mathrm{~mm} \\ \text { Rotor outer diameter } & 248 \mathrm{~mm} \\ \text { Stator inner diameter } & 250 \mathrm{~mm} \\ \text { Stator outer diameter } & 365 \mathrm{~mm} \\ \text { Stack length } & 190 \mathrm{~mm} \\ \text { Air gap } & 1 \mathrm{~mm} \\ \text { Slots } & 48 \\ \text { Pole pairs } & 4 \\ \text { Tooth width } & 10.2 \mathrm{~mm} \\ \text { Slot height } & 38.1 \mathrm{~mm} \\ \text { Slot opening width } & 3 \mathrm{~mm}\end{array}$

The outer volume as well as all the stator sizes of the machine have been fixed in order to satisfy requirements for a certain application (light railway), and has been kept constant through all the proposed geometries. The only part that has been modified then, is the rotor geometry and the PMs volume.

\section{B. Sensitivity Analysis on Initial Case Study Geometries}

To start the analysis, some random geometries have been selected (T1, T2, T3); these have been reported in Fig. 3. 
The analysis of these three initial designs has been divided in two different steps: the first one is the study of the air gap flux density in no load condition and the second one is the study of the behaviour of the three topologies in terms of power capabilities in a certain speed range.

The results in terms of no-load air gap flux density waveform have been reported in Fig. 4; the harmonic content reported in Fig. 5, has been evaluated using a Fourier Fast Transform (FFT) method, that allows to better compare the results.

As it can be seen from Fig. 4, there are some big differences in terms of waveform shape for the three different topologies. Starting from T3, it presents a no-load air gap flux density average value $\left(B_{\text {avg }}\right)$ equal to $0.45 \mathrm{~T}$ that is the lowest value among the three geometries here studied, and a THD value equal to $43 \%$. T2 is somewhere in between T3 and T1, with a

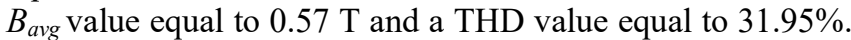

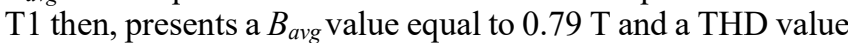
of $39.6 \%$. The difference in terms of shape of the waveform strictly depends from the rotor PM and barriers arrangement: $\mathrm{T} 2$ presents a peak between $15^{\circ}$ and $30^{\circ}$ that is caused by the bigger size and the position closer to the air gap of the first barrier, in respect to the $\mathrm{T} 3$ design that presents a flatter waveform. T1 presents even a slightly more extended peak region $\left(14^{\circ}-31^{\circ}\right)$ with a higher value for the plateau region given by the bigger PM amount present in the second level barriers, compared to T2. Finally, all three designs present 6 drops, due to the stator slot openings effect ( 6 slots per pole).

The harmonics content behaviour is not linear passing from $\mathrm{T} 3$ to $\mathrm{T} 1$, and in particular some harmonics such as the $11^{\text {th }}$ or the $23^{\text {rd }}$ present a different proportion between the three designs. In addition, the $3^{\text {rd }}$ harmonic content for T2 (blue) is completely absent unlike T1 and T3. This is highlighted also from the THD value that spans from $31.95 \%$ (T2) to $43 \%$ (T3), passing by $39.6 \%$ (T1).

The last step of the study of T1, T2 and T3 consists in analysing power capabilities for each design and compare the results in terms of flux components. The electrical constraints that have been selected in order to complete the three designcharacterization are reported in Table II. The speed range that is required is quite wide, taking into account that the base

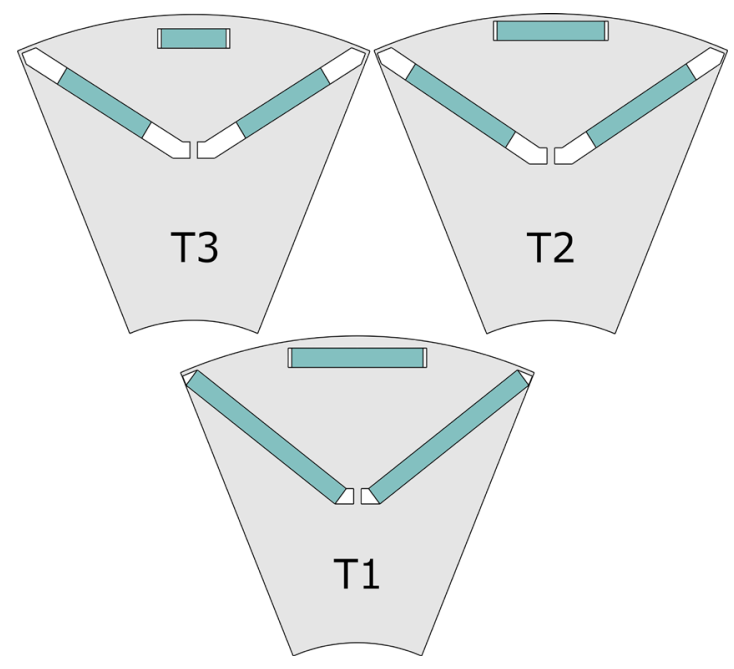

Figure 3: sketch of the three initial rotor geometries

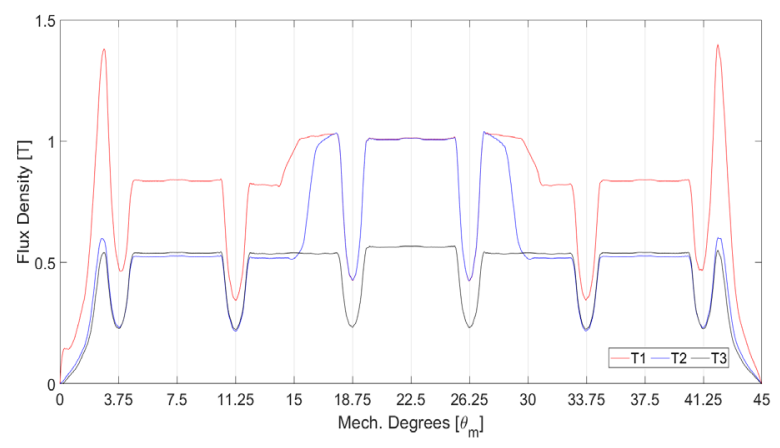

Figure 4: no-load air gap flux density waveforms for the three initial topologies

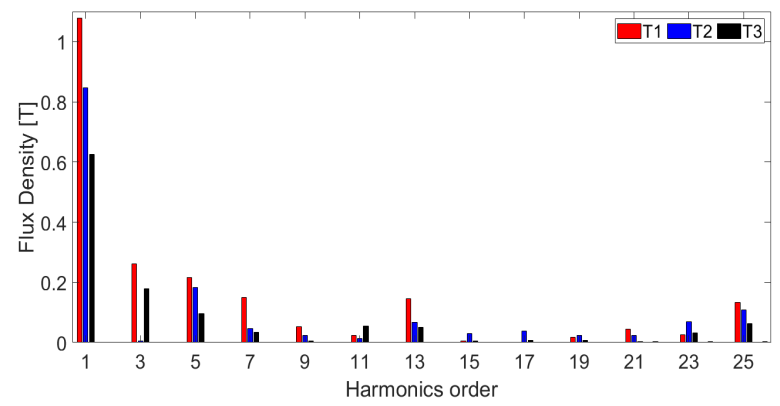

Figure 5: FFT analysis of the no-load air gap flux density for the three initial topologies

speed is set to $3000 \mathrm{rpm}$ and the max operating speed is three times this value.

Table II: electrical specifications

\begin{tabular}{cc}
\hline \multicolumn{2}{c}{ E-machine electrical specifications } \\
\hline \hline Max Phase current & $535 \mathrm{Apk}_{\mathrm{pk}}$ \\
Nominal Phase current & $356 \mathrm{Apk}$ \\
DC link Voltage & $650 \mathrm{~V}_{\mathrm{dc}}$ \\
Base speed & $3000 \mathrm{rpm}$ \\
Max speed & $9000 \mathrm{rpm}$ \\
Max torque & $1090 \mathrm{Nm}$ \\
Nominal power & $180 \mathrm{~kW}$
\end{tabular}

The final conclusion for this preliminary sensitivity analysis is that the no-load air gap flux density waveforms present a behaviour that reflects what it was expected from the rotor geometry modification; the harmonics content instead, does not present a straightforward correlation between rotor design and flux density harmonics results.

\section{Power Capability}

As it has been discussed in [18-20] the flux weakening capability is defined as the ratio of maximum speed to the base-speed, under voltage and current limitations. Usually traction machines are required to operate at wide operating speed range [21].

In [18] the flux-weakening capability of PM machines has been studied; It was shown that the maximum flux weakening capability can be achieved if the machine is designed to have a per unit q-axis inductance and pm-flux as:

$$
\frac{L_{q} i_{q}}{\psi_{p m}} \geq 1
$$


Where $L_{q}$ is the $q$-axis inductance, $i_{q}$ is the $q$-axis current and $\psi_{p m}$ is the stator flux linkage related to the PMs. The higher the ratio (2), the wider the speed range that can be achieved.

The SPM machines are usually not good candidates in order to achieve this requirement, as the inductance in $q$-axis is usually low. Hence the IPM machines are more suitable for such applications that require a wide speed range. However, if the designed machine's cooling capability allow higher current ratings, the requirement of a high value for the ratio expressed in (2) can be achieved even for SPM topology as demonstrated in [22].

The following example demonstrates the power capability of the 3 topologies that are shown in Figure 3. All three machines have been fed based on the requirements shown in Table III. Figure 6 presents the power capability curves on the left-hand side and flux linkages on the right-hand side for all three options.

As it can be observed, all three machines are capable to operate at the maximum speed at constant power. However, all machines achieve this condition at different operating currents. As shown on Figure 6 b) for T1 the requirement (2) is satisfied at the highest current value ( $\mathrm{I}=535 \mathrm{~A}$ ). Hence, the constant power region is achieved at this condition as it can be seen in Figure 6 a). Whereas, T2 and T3, that are shown respectively in Figure $6 \mathrm{c}$ ) and e), are capable to operate with constant power at lower currents. T2 is reaching the voltage limit at $\mathrm{I}=535 \mathrm{~A}$ and $\mathrm{T} 3$ is reaching the voltage limit at $\mathrm{I}=356$ A. After this study, a further set of simulations have been completed, in order to collect some more information regarding the machines: in this case a slot current density of $7 \mathrm{~A} / \mathrm{mm}^{2}$ has been set.

In Table III PMs weight, ripple, average torque value and ratio between average torque and PMs weight have been reported for each topology: since the machines that have been analyzed so far don't present any kind of optimization but are simply random generated, the torque ripple values are way too high for every possible application.

At first sight, higher is PMs weight (column 2), higher is the achievable torque value (column 3 ), but it's interesting to notice that the ratio between the average torque value and the PMs weight (column 5) is not linearly proportional: T2, that presents an average torque value lower than $\mathrm{T} 1$, presents
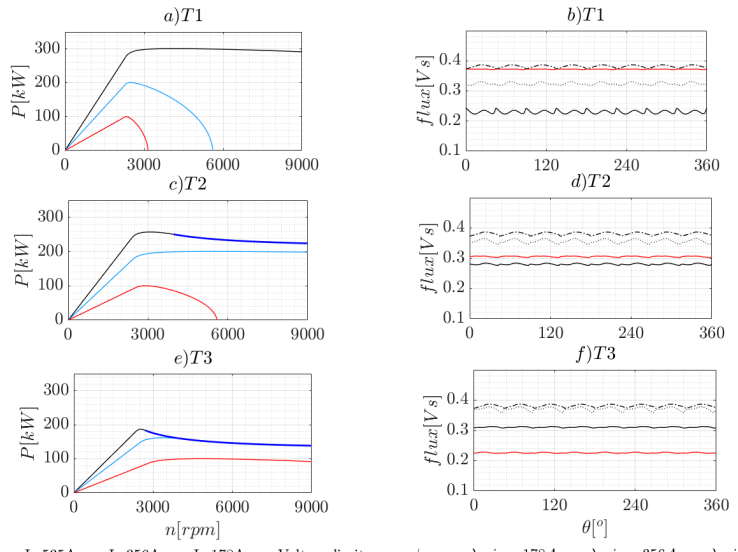

$-\mathrm{I}=535 \mathrm{~A}-\mathrm{I}=356 \mathrm{~A}-\mathrm{I}=178 \mathrm{~A}-$ Voltage lin

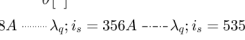

Figure 6: Power capability evaluation of T1, T2 and T3
$+21 \%$ in terms of PMs specific torque value (from 166 to 200 $\mathrm{Nm} / \mathrm{kg}$ ).

Table III, results for T1, T2 and T3

\begin{tabular}{ccccc}
\hline Name & $\begin{array}{c}\text { PMs } \\
\text { weight } \\
{[\mathrm{Kg}]}\end{array}$ & $\begin{array}{c}\text { T avg } \\
{[\mathrm{Nm}]}\end{array}$ & $\begin{array}{c}\text { Ripple } \\
{[\%]}\end{array}$ & $\begin{array}{c}\text { PM Spec. } \\
\text { Torque } \\
{[\mathrm{Nm} / \mathrm{kg}]}\end{array}$ \\
\hline \hline T1 & 7.74 & 1281 & 34.61 & 166 \\
T2 & 5.29 & 1059 & 50.24 & 200 \\
T3 & 4.03 & 798 & 25.50 & 198
\end{tabular}

These preliminary results clearly demonstrate that there is room for improvement in order to achieve better results in terms of torque ripple value and average torque value. For this reason, an optimization has been set.

\section{OPTIMISATION}

Considering the findings presented in the previous section, it is worth to explore further the capability of this type of motor. For this purpose, a Multi Objective Genetic Algorithm (MOGA-II) has been linked with an automatic drawing and solving procedure implemented via Matlab and the finite element software FEMM 4.2. The optimization software used is ModeFrontier, which is a flexible tool that integrates several genetic algorithms and can simply connect different software packages [23]. The target of this work is to optimize the $\nabla$-shaped rotor geometry with the input variables summarized in Table IV. The FE-based design optimization workflow is shown in Fig. 7. The initial Design of Experiments (DOE) table used to start the search has been defined by a Sobol sequence.

The number of individuals for each generation has been set to 100 and a maximum of 60 generations has been considered leading to a total of 6000 functional evaluations. The stator geometry has been fixed to the values reported in Table I, and the focus is given to the optimization of the rotor only. The input variables considered for the optimization of the rotor structure are reported in Table IV.

The objectives were to maximize average torque value and to minimize the overall losses and the torque oscillations. In addition, considering the previous analysis on the no-load air gap flux density harmonic component, also a number of harmonics $\left(h=1^{\text {st }}-29^{\text {th }}\right)$ has been monitored and saved for each

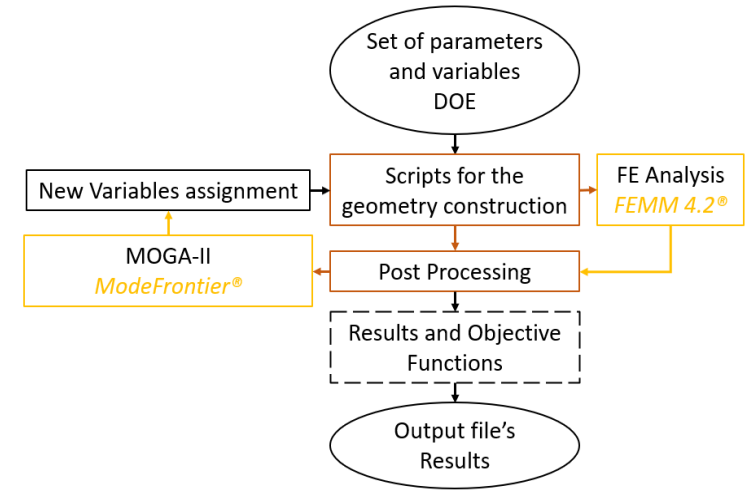

Figure 7: Ontimization process workflow 


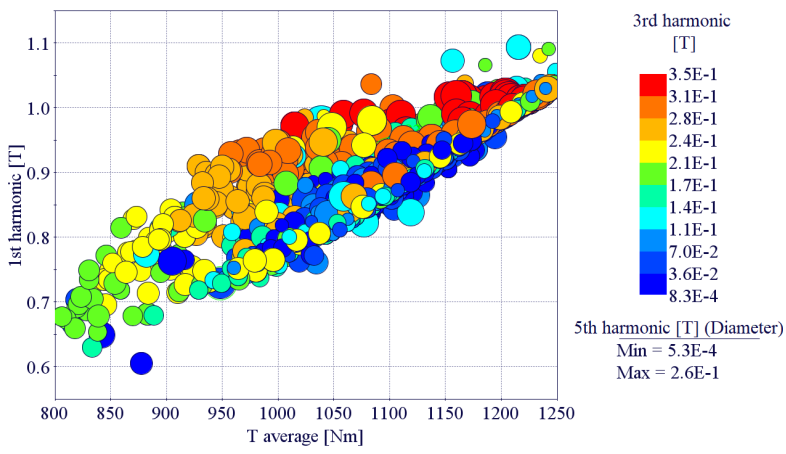

Figure 8: Optimisation results chart, showing average torque vs 1st (Y-axis), 3rd (colour scale) and 5th (circle diameter) harmonics

solution. The optimization results are summarized in Figs. 8 and 9.

Table IV, Input variables and range

\begin{tabular}{ccc}
\hline \multirow{2}{*}{ Parameter } & \multicolumn{2}{c}{ Boundaries } \\
\cline { 2 - 3 } & Lower & Upper \\
\hline $\mathrm{h}_{\mathrm{b} 1 \mathrm{pu}}$ & 0 & 0.5 \\
$\mathrm{~h}_{\mathrm{b} 2 \mathrm{pu}}$ & 0.01 & 0.5 \\
$\alpha_{\mathrm{m} 1 \mathrm{pu}}$ & 0.2 & 1.0 \\
$\alpha_{\mathrm{m} 2 \mathrm{pu}}$ & 0.1 & 0.95 \\
$\mathrm{~W}_{\mathrm{m} 2 \mathrm{pu}}$ & 0.5 & 1.0
\end{tabular}

In Fig. 8 the solutions have been reported indicating in $\mathrm{X}$ axis the average torque value and in $\mathrm{Y}$-axis the $1^{\text {st }}$ harmonic component; colour scale and circle diameters indicates the $3^{\text {rd }}$ and $5^{\text {th }}$ harmonics, respectively. Looking at the designs that fulfil the torque requirement stated in Table II $\left(\mathrm{T}_{\mathrm{avg}}=1090\right.$ $\mathrm{Nm}$ ), is interesting to see how a completely different harmonics distribution can lead to the same value in terms of available torque.

The machine targets in terms of available torque and torque ripple have been set respectively to $1090 \mathrm{Nm}$ as already reported, and a range between $10 \%$ and $15 \%$ for torque ripple, with a slot current density equal to $7 \mathrm{~A} / \mathrm{mm}^{2}$. In Fig. 9, the red square indicates the designs that fulfil the above-cited requirements out of all the solutions found through the optimization procedure.

From the highlighted solutions, three machines (M1-M3) have been selected, to compare these with the first three geometries (T1-T3); the first analysis that has been completed, gives some insights in terms of PMs weight and torque ripple, as it has been already done for T1, T2 and T3 in Table III. Results can be found in Table IV.

The ripple fulfils the requirement in all 3 machines and the torque value is almost identical. The biggest difference can be noticed in the PM weight and consequently in the PM specific torque value: comparing M1 with M2, the difference in terms of average torque is less than $0.5 \%$, but in $\mathrm{M} 2$ the $\mathrm{PM}$ weight is reduced by $11 \%$ in respect to $\mathrm{M} 1$. This leads to a cheaper machine, with almost the same rated torque.

Finally, the power capability of M1, M2 and M3 has been investigated using the same operating conditions reported in Table II. All three machines can reach the required values in

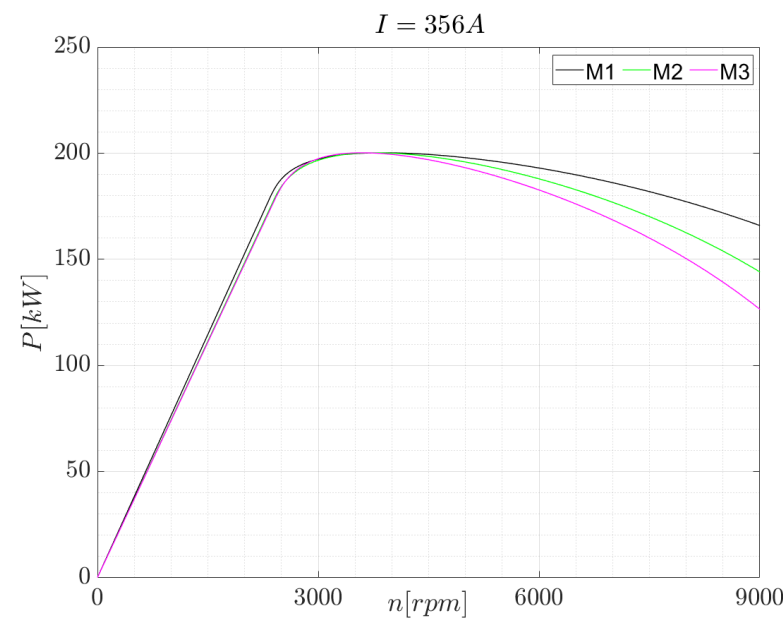

Figure 10: Power capability evaluation of M1, M2 and M3

terms of power and torque. In Fig. 10 are reported the power vs speed curves for the rated phase current (356 A), and is interesting to notice that the M2 machine has an higher power value at max speed $(145.5 \mathrm{~kW})$ compared to M3 $(126.8 \mathrm{~kW})$ that corresponds to an increase in terms of power of c.a. $13 \%$, even if the amount of PMs is lower in M2 than in M3 of c.a. $7 \%$.

The curve that is shown in Fig. 10 represents the entire power capability of the three machines, only for rated phase current value: in this specific application, the required power value at base speed $(3000 \mathrm{rpm})$ is equal to $180 \mathrm{~kW}$, that can be provided by all the presented geometries. The simulations for the other two conditions presented for T1, T2 and T3 (178 $\mathrm{A}$ and $535 \mathrm{~A}$ ) have been omitted because of their behavior that is very similar to the waveforms already presented in Fig.6.

Table V, results for optimized designs (M1-M3)

\begin{tabular}{ccccc}
\hline Name & $\begin{array}{c}\text { PMs } \\
\text { weight } \\
{[\mathrm{kg}]}\end{array}$ & $\begin{array}{c}\text { T avg } \\
{[\mathrm{Nm}]}\end{array}$ & $\begin{array}{c}\text { Ripple } \\
{[\%]}\end{array}$ & $\begin{array}{c}\text { PM Spec. } \\
\text { Torque } \\
{[\mathrm{Nm} / \mathrm{kg}]}\end{array}$ \\
\hline \hline M1 & 7.25 & 1099 & 12.61 & 152 \\
M2 & 6.45 & 1094 & 13.19 & 170 \\
M3 & 6.90 & 1096 & 13.12 & 159
\end{tabular}

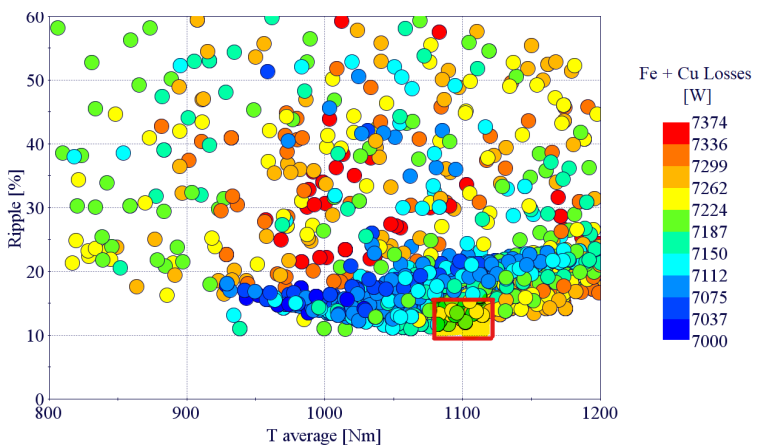

Figure 9: Optimisation results chart, showing average torque vs torque ripple (Y-axis) and $\mathrm{Fe}+\mathrm{Cu}$ losses (colour scale) 


\section{CONCLUSIONS}

The aim of this work is to analyse a $\nabla$-shaped IPMSM based on a complete parametrization that has been here presented. Based on a preliminary sensitivity analysis, three initial topologies (T1, T2, T3) have been studied in detail looking at their no-load air gap flux density waveforms and harmonics content, comparing also their THD values. After this first step, a specific application has been targeted, with certain requirements in terms of external geometrical dimensions of the machine (the same stator has been used for all the studied geometries), electrical constraints (phase current) and mechanical output (power and torque values, base and max speed, etc.)

Finally, their power capabilities for the specific application have been presented, clearly demonstrating that the higher is the ratio expressed in (2), the wider is the speed range that the machine can achieve.

A complete optimisation using a combination of FE-based simulations, Matlab scripting and an optimisation tool (ModeFrontier) has been done for a specific operating point, using as main objective functions the average torque maximisation, while reducing losses and torque ripple. From Fig. 8 is vivid that the same average torque value can be achieved with a number of different harmonics distribution: this can be helpful in specific conditions in which a specific harmonics distribution is required.

From the optimisation results obtained, three geometries have been selected (M1, M2, M3) to further analyse their behaviour in terms of power capabilities over the whole speed range. Taking into account what has been expressed in Fig.1 for the public transport sector, the best solution is M2 since this one presents the lowest PMs weight value. The weight itself is not the main concern, but the cost is strictly related to the PMs weight, and for this reason the above-mentioned solution can be considered the most cost-effective. In conclusion, for this kind of motors with a non-conventional rotor shape, an optimisation procedure is always recommended, in order to achieve satisfying results.

\section{REFERENCES}

[1] E. Commission, "EU transport in figures- Statistical pocketbook 2019" European Commission, Bruxelles 2019.

[2] E. E. Agency, "Almost all car makers met their 2017 CO2 emission targets on new sales, but overall progress towards the 2021 targets is insufficient" European Environment Agency Website, Accessed on: Apr.Available: : https://www.eea.europa.eu/highlights/almost-all-carmakers-met-their.

[3] D. Ronanki, S. A. Singh and S. S. Williamson, "Comprehensive Topological Overview of Rolling Stock Architectures and Recent Trends in Electric Railway Traction Systems," in IEEE Transactions on Transportation Electrification, vol. 3, no. 3, pp. 724-738, Sept. 2017 , doi: 10.1109/TTE.2017.2703583.

[4] B. Sarlioglu and C. T. Morris, "More Electric Aircraft: Review, Challenges, and Opportunities for Commercial Transport Aircraft," in IEEE Transactions on Transportation Electrification, vol. 1, no. 1, pp. 54-64, June 2015, doi: 10.1109/TTE.2015.2426499.

[5] B. Frieske, M. Kloetzke and F. Mauser, "Trends in vehicle concept and key technology development for hybrid and battery electric vehicles," 2013 World Electric Vehicle Symposium and Exhibition (EVS27), Barcelona, 2013, pp. 1-12, doi: 10.1109/EVS.2013.6914783.

[6] E. Sayed, Y. Yang, B. Bilgin, M. H. Bakr and A. Emadi, "A Comprehensive Review of Flux Barriers in Interior Permanent Magnet Synchronous Machines" in IEEE Access, vol. 7, pp. 149168-149181, 2019, doi: 10.1109/ACCESS.2019.2947047.
[7] K. Yoon and B. Kwon, "Optimal Design of a New Interior Permanent Magnet Motor Using a Flared-Shape Arrangement of Ferrite Magnets" in IEEE Transactions on Magnetics, vol. 52, no. 7, pp. 1-4, July 2016, Art no. 8106504, doi: 10.1109/TMAG.2016.2524505.

[8] K. Chiba, M. Takemoto, S. Ogasawara and W. G. Yim, "Ferrite-magnet spoke-type IPMSM with W-shaped magnet placement," IECON 2013 - 39th Annual Conference of the IEEE Industrial Electronics Society, Vienna, 2013, pp. 2869-2874, doi: 10.1109/IECON.2013.6699586.

[9] Y. Jung, M. Park and M. Lim, "Asymmetric Rotor Design of IPMSM for Vibration Reduction Under Certain Load Condition" in IEEE Transactions on Energy Conversion, doi: 10.1109/TEC.2020.2966299.

[10] W. Zhao, F. Zhao, T. A. Lipo and B. Kwon, "Optimal Design of a Novel V-Type Interior Permanent Magnet Motor with Assisted Barriers for the Improvement of Torque Characteristics" in IEEE Transactions on Magnetics, vol. 50, no. 11, pp. 1-4, Nov. 2014, Art no. 8104504, doi: 10.1109/TMAG.2014.2330339.

[11] R. Akune, K. Akatsu, M. Fujihara and T. Yamamoto, "Study of high torque density interior permanent magnet synchronous motor with flexible orientation Nd2Fe14B sintered magnet" 2016 XXII International Conference on Electrical Machines (ICEM), Lausanne, 2016, pp. 578-584, doi: 10.1109/ICELMACH.2016.7732584.

[12] S. Zhu, W. Chen, M. Xie, C. Liu and K. Wang, "Electromagnetic Performance Comparison of Multi-Layered Interior Permanent Magnet Machines for EV Traction Applications," in IEEE Transactions on Magnetics, vol. 54, no. 11, pp. 1-5, Nov. 2018, Art no. 8104805, doi: 10.1109/TMAG.2018.2841851.

[13] Y. Hu, S. Zhu, C. Liu and K. Wang, "Electromagnetic Performance Analysis of Interior PM Machines for Electric Vehicle Applications," in IEEE Transactions on Energy Conversion, vol. 33, no. 1, pp. 199208, March 2018, doi: 10.1109/TEC.2017.2728689.

[14] Y. Kano, "Torque Ripple Reduction of Saliency-Based Sensorless Drive Concentrated-Winding IPMSM Using Novel Flux Barrier," in IEEE Transactions on Industry Applications, vol. 51, no. 4, pp. 29052916, July-Aug. 2015, doi: 10.1109/TIA.2015.2391431.

[15] J. Han, J. Lee and W. Kim, "A Study on Optimal Design of the Triangle Type Permanent Magnet in IPMSM Rotor by Using the Box-Behnken Design," in IEEE Transactions on Magnetics, vol. 51, no. 3, pp. 1-4, March 2015, Art no. 8200704, doi: 10.1109/TMAG.2014.2362576.

[16] H. Chen and C. H. T. Lee, "Parametric Sensitivity Analysis and Design Optimization of an Interior Permanent Magnet Synchronous Motor," in IEEE Access, vol. 7, pp. 159918-159929, 2019, doi: 10.1109/ACCESS.2019.2950773.

[17] L. Tian, L. Wu, X. Huang and Y. Fang, "Driving range parametric analysis of electric vehicles driven by interior permanent magnet motors considering driving cycles," in CES Transactions on Electrical Machines and Systems, vol. 3, no. 4, pp. 377-381, Dec. 2019, doi: 10.30941/CESTEMS.2019.00049.

[18] Z. Q. Zhu and D. Howe, "Electrical Machines and Drives for Electric, Hybrid, and Fuel Cell Vehicles," in Proceedings of the IEEE, vol. 95, no. 4, pp. 746-765, April 2007, doi: 10.1109/JPROC.2006.892482.

[19] W. L. Soong and N. Ertugrul, "Field-weakening performance of interior permanent-magnet motors," in IEEE Transactions on Industry Applications, vol. 38, no. 5, pp. 1251-1258, Sept.-Oct. 2002, doi: 10.1109/TIA.2002.803013.

[20] R. F. Schiferl and T. A. Lipo, "Power capability of salient pole permanent magnet synchronous motors in variable speed drive application", IEEE Trans. Ind. Appl., vol.26, no. 1, pp. 115-123, Jan./Feb. 1990.

[21] Y. S. Chen, Z. Q. Zhu, and D. Howe, "Influence of inaccuracies in machine parameters on field-weakening control performance of PM brushless drives", in Proc. IEEE Int. Electric Machines \& Drives Conf., Seattle, WA, 1999, pp. 691-693.

[22] A. M. EL-Refaie and T. M. Jahns, "Optimal flux weakening in surface PM machines using fractional-slot concentrated windings" in IEEE Transactions on Industry Applications, vol. 41, no. 3, pp. 790-800, May-June 2005, doi: 10.1109/TIA.2005.847312.

[23] G. Poloni and V. Pediroda, "GA Coupled with Computationally Expensive Simulations: Tools to Improve Efficiency" in Genetic Algorithms and Evolution Strategy in Engineering and Computer Science: Recent Advances and Industrial Applications, D. Quagliarella, J. Periaux, C. Poloni, G. Winter, John Wiley\&Sons, 2000. 